\title{
Pre- and Post-Operative Intraocular Pressure of Pediatric Cataract Surgery
}

\author{
Reyhana Khansa Mawardi ${ }^{1} \mathbb{D}$, Dicky Hermawan ${ }^{2} \mathbb{D}$, Kristanti Wanito Wigati ${ }^{3} \mathbb{D}$, \\ Rozalina Loebis ${ }^{2} \mathbb{D}$
}

${ }^{1}$ Faculty of Medicine, Universitas Airlangga, Surabaya, Indonesia.

2Department of Ophthalmology, Faculty of Medicine, Universitas Airlangga/Dr. Soetomo General Hospital, Surabaya, Indonesia. ${ }^{3}$ Department of Physiology and Biochemistry, Universitas Airlangga, Surabaya, Indonesia.

\section{A B S T R A C T}

Introduction: Cataract is an eye lens opacification which prevents clear vision. It is the leading cause of blindness and vision impairment worldwide, including Indonesia. It can also be occurred in children that leads to a major cause of childhood blindness. The prevalence of childhood cataract ranges from 3 to 6 per 10,000 children. The main treatment for cataract is surgery, although pediatric cataract surgery has several complications. One of the most severe complication is glaucoma due to increased intraocular pressure (IOP). This study aimed to determine pre- and postoperative IOP in pediatric cataract surgery.

Methods: This was a cross-sectional observational analytic study. Secondary data were collected from medical records of Department of Ophthalmology, Dr. Soetomo General Hospital Surabaya from January 2017 to August 2019. Age, gender, preand post-operative IOP, and intraocular lens implantation data were taken. Calculation was performed using the Saphiro-Wilk for data less than 50 samples. The Saphiro-Wilk test results showed that the data were normally distributed $(p=$ 0.628 ). Data processing were then performed using the parametric t-pair test with a confidence level of

Results: 32 eye samples were obtained from 16 pediatric cataract surgery patients. The mean of pre-operative IOP was $13.05 \mathrm{mmHg}$ and the mean of post-operative IOP was $13.36 \mathrm{mmHg}$. There was an increase in post-operative IOP with an average increase of $0.31 \mathrm{mmHg}$. There was no significant difference between pre- and postoperative IOP of pediatric cataract surgery patients $(p=0.711)$.

Conclusion: There was no difference between pre- and post-operative IOP of pediatric cataract surgery patients at Dr. Soetomo General Hospital Surabaya for the period of January 2017 - August 2019.

\footnotetext{
* Correspondence: dicky.hermawan@fk.unair.ac.id
}

JUXTA: Jurnal Ilmiah Mahasiswa Kedokteran Universitas Airlangga

p-ISSN: 1907-3623; e-ISSN: 2684-9453

DOI: $10.20473 /$ juxta.V13I12022.22-26

Open access under Creative Commons Attribution-ShareAlike 4.0 International License (CC-BY-SA)
ARTICLEINFO

Article history:

Received 15 October 2021

Received in revised form 14

December 2021

Accepted 28 December 2021

Available online 5 January 2022

\section{Keywords:}

Cataract surgery,

Child mortality,

Intraocular pressure,

Pediatric. 


\section{Introduction}

Cataract is a clouding of the lens in the eye that can impair eye vision. It may be partial or complete and can occur in one or both eyes. It is the leading cause of blindness and visual impairment worldwide. According to WHO, ${ }^{1} 95$ million people worldwide had experienced vision impairment due to cataracts. It is responsible for $51 \%$ of world blindness, which represents about 20 million people, and is expected to reach 40 million people worldwide by 2020.

In Indonesia, blindness due to cataracts is still quite high, reaching $3 \%$ of the population. ${ }^{2}$ Most cataract cases are related to an aging process, but some of them are also caused by several other causes, such as eye injury, inflammation, and several other eye disorders. Cataracts can also be suffered by children. Around 70 million vision loss in the world occurred early in childhood, and 10 million $(14 \%)$ of them are due to cataracts. ${ }^{3}$ Pediatric cataracts affect around 200,000 children worldwide, with prevalence ranging from 3 to 6 per 10,000 live births. This causes pediatric cataracts to be the leading cause of blindness in children. ${ }^{4}$

The treatment of choice for cataract is eye surgery with an extraction of the defect lens, then replaced by an artificial intraocular lens. With the right techniques, cataract surgery can lead to a good result. However, pediatric cataract surgery has several complications and one of the most severe one is glaucoma. Glaucoma is caused by an abnormal increase of intraocular pressure (IOP). According to Parks, et $a /,{ }^{5}$ in children who have had cataract surgery without intraocular lens implantation at more than 2 months of age, about 54\% suffer from aphakic glaucoma. According to Rabiah, et al., ${ }^{6}$ children who underwent cataract surgery at the age of 9 months, $37 \%$ were more likely to suffer from glaucoma compared to $6 \%$ of children who underwent surgery after 9 months old. According to Vishwanath, et al., ${ }^{7}$ children who have had bilateral cataract surgery in the first month of life were $50 \%$ more likely to suffer from glaucoma compared to $15 \%$ of children who underwent surgery later.

Hence, pediatric cataract surgery has some serious complications and one of them is glaucoma which has a clinical sign of increased IOP. Therefore, conducting research on the comparison of pre- and post-operative IOP in pediatric cataract surgery was the point of interest of this study.

\section{Methods}

This was a cross-sectional observational analytic study to determine the differences in pre- and post-operative IOP in pediatric cataract surgery. Secondary data were collected from medical records of Department of Ophthalmology, Dr. Soetomo General Hospital Surabaya from January 2017 to August 2019.
The study population included all pediatric cataract surgery patients at Dr. Soetomo General Hospital Surabaya from 1 January 2017 to 31 August 2019. Total sampling was used for patients who met the inclusion criteria. Exclusion criteria was incomplete data in the medical record.

Variables included age, gender, pre- and postoperative IOP, and intraocular lens implantation. Data processing and analyzing were performed using Microsoft Excel and IBM SPSS Statistic version 23 and represented in tables.

IOP was measured using a schiotz tonometer moments before surgery after the anaesthesia. Subjects were divided into two age groups of less and more than 24 months. This division was based on different opinion between ophthalmologists about intraocular lens placement in pediatric cataract surgery. Younger patients tend to have a non-optimal ocular size, hence an intraocular lens implantation will tighten the space inside. An optimal development of the ocular size will be reached at the age of 2 years old.

\section{Results}

General Characteristics of Children Underwent Pediatric Cataract Surgery

From 16 pediatric patients, it was found that the most pediatric cataract surgery patients varied from 1 month old to 2 years old (11 patients, $68.8 \%$ ), males ( 9 patients, $56.3 \%$ ), and had an intraocular lens implantation (24 of 32 eyes, $75 \%$ ).

Table 1. General characteristics

\begin{tabular}{lcc}
\hline \multicolumn{1}{c}{ Characteristics } & $\mathbf{n}$ & $\%$ \\
\hline Age & & \\
$\quad$ Neonate (0 to 1 month old) & 0 & 0 \\
Infant (1 month to 2 years old) & 11 & 68.8 \\
Young child (2 to 6 years old) & 2 & 12.5 \\
Child (6 to 12 years old) & 0 & 0 \\
$\quad$ Adolescent (12 to 18 years old) & 3 & 18.7 \\
\hline TOTAL (Patient) & $\mathbf{1 6}$ & $\mathbf{1 0 0}$ \\
\hline Gender & & \\
$\quad$ Male & 9 & 56.3 \\
$\quad$ Female & 7 & 43.7 \\
\hline TOTAL (Patient) & $\mathbf{1 6}$ & $\mathbf{1 0 0}$ \\
\hline Intraocular lens implantation complication & \\
$\quad$ Aphakic & 8 & 25 \\
$\quad$ Pseudophakic & 24 & 75 \\
\hline TOTAL (Eye) & $\mathbf{3 2}$ & $\mathbf{1 0 0}$ \\
\hline
\end{tabular}

Source: Research data, processed

Table 2. Comparison of pre- and post-operative IOP of pediatric cataract surgery

\begin{tabular}{lcccc}
\hline $\begin{array}{c}\text { Intraocular } \\
\text { Pressure }\end{array}$ & $\begin{array}{c}\text { Oculi } \\
\text { (n) }\end{array}$ & $\begin{array}{c}\text { Mean } \\
(\mathbf{m m H g})\end{array}$ & $\begin{array}{c}\text { Deviation } \\
\text { standard } \\
\text { (mmHg) }\end{array}$ & $\begin{array}{c}\text { P- } \\
\text { value }\end{array}$ \\
\hline All & & & & \\
Pre-operative & 32 & 13.05 & 3.36 & 0.771 \\
Post-operative & 32 & 13.36 & 3.39 & \\
\hline $\begin{array}{l}\text { Younger than } \\
\text { 24 months old }\end{array}$ & & & & \\
\end{tabular}




\begin{tabular}{lllll} 
Pre-operative & 20 & 12.39 & 3.50 & \\
Post-operative & 20 & 13.58 & 3.56 & 0.197 \\
\hline $\begin{array}{l}\text { Older than 24 } \\
\text { months old }\end{array}$ & & & & \\
$\begin{array}{l}\text { Pre-operative } \\
\text { Post-operative }\end{array}$ & 12 & 14.15 & 2.92 & \\
\hline Aphakic & & 13.00 & 3.21 & 0.494 \\
$\begin{array}{l}\text { Pre-operative } \\
\text { Post-operative }\end{array}$ & 8 & 10.63 & 3.15 & \\
\hline Pseudophakic & & 12.29 & 3.89 & 0.307 \\
$\begin{array}{l}\text { Pre-operative } \\
\text { Post-operative }\end{array}$ & 24 & 13.86 & 3.08 & \\
\hline Source:Research & 24 & 13.72 & 3.21 & 0.891 \\
\hline
\end{tabular}

Source: Research data, processed

\section{Comparison of Pre- and Post-operative IOP of Pediatric Cataract Surgery}

The Saphiro-Wilk test results showed a p-value of 0.628 , a normal distribution value $(p>0.05)$. Data processing was then performed using the paired parametric t-test with a confidence level of 95\%. Comparison of pre- and post-operative IOP in pediatric cataract surgery showed a pre-operative IOP mean of $13.05 \mathrm{mmHg}$ and a post-operative IOP mean of 13.36 $\mathrm{mmHg}$ with a $\mathrm{p}$ - value of 0.711 .

Comparisons in between each age group of younger and older than 24 months old showed no significant results. In the age group of patients younger than 24 months old, accounts for 20 eyes, the mean of pre-operative IOP were $12.39 \mathrm{mmHg}$ and the post-operative IOP were $13.58 \mathrm{mmHg}$ with a $p$ value of 0.197 . In the age group of patients older than 24 months old, accounts for 12 eyes, the mean of preoperative IOP were $14.15 \mathrm{mmHg}$ and the post-operative IOP were $13.00 \mathrm{mmHg}$ with a $\mathrm{p}$ value of 0.494 .

Comparisons were also performed in between group of aphakic and pseudophakic patients. In the aphakic group, accounts for 8 eyes, the mean of pre-operative IOP were $10.63 \mathrm{mmHg}$ and the post-operative IOP were 12.29 $\mathrm{mmHg}$ with a $\mathrm{p}$ value of 0.307 . In the pseudophakic group, accounts for 24 eyes, the mean of pre-operative IOP were $13.86 \mathrm{mmHg}$ and the post-operative IOP were $13.72 \mathrm{mmHg}$ with a $p$ value of 0.891 .

\section{Discussion}

The results showed that the age distribution of most pediatric cataract surgery patients was in the age group of 1 month old to 2 years old, as much as 11 patients $(68.8 \%)$. This distribution domination might be due to the optimal time to perform cataract surgery, which is around the age of 4 to 8 weeks old. Cataract surgeries performed on children younger than 4 weeks old can increase the risk of secondary glaucoma. ${ }^{8}$ According to Khokar, et al., ${ }^{3}$ cataract surgeries performed on children under 7 months old can increase the risk of glaucoma. However, this result differs from Wenwen $\mathrm{He}$, et al. ${ }^{9}$ who stated that the most age in pediatric cataract surgery in Shanghai was between 2 to 6 years old $(53.75 \%)$ and not of the age of 1 month old to 2 years old $(21.43 \%)$. Lin, et al. ${ }^{10}$ also stated that the most pediatric cataract surgery patients at the Zhongshan Ophthalmic Center (ZOC) was in the age group of 2 to 6 years old $(29.22 \%)$ and not in the age group of 1 month old to 2 years old (19.23\%). This difference in age distribution

may be due to differences in sample size and sociodemographic characteristics in each study.

Patients were dominated by male children, as much as 9 patients (56\%). This is likely due to differences in care patterns for boys and girls. ${ }^{11}$ In addition, there are studies stated that in Tanzania, girls are indeed more likely to delay treatment than boys. ${ }^{12}$ Until now, there has been no comprehensive study that confirms that genetic factors might affect boys' tendency in developing cataracts. ${ }^{11}$ The results of this study did not differ from the study of Wenwen $\mathrm{He}$, et al., ${ }^{9}$ which stated that the most sex in pediatric cataract surgery patients in Shanghai were male with 296 of 493 cases (60\%). According to Repka, et al., ${ }^{13}$ male also dominated the pediatric cataract surgery in 504 of 994 cases $(51 \%)$. Katibeh, et al. ${ }^{11}$ also stated that the incidence of pediatric cataracts in boys is $10 \%$ higher than in girls (54.8\% vs $44.2 \%)$. Gilbert and Chomette ${ }^{12}$ also found that of 6,854 patients with bilateral pediatric cataract surgery, only $2,505(36.5 \%)$ were female. Many developing countries have the same gender pattern in which $2 / 3$ of the total number of pediatric cataract operations are performed on boys. ${ }^{11}$

Based on the obtained data, all patients with pediatric cataract surgery suffered from bilateral cataracts, thus the surgery should be performed on both eyes as soon as possible. This might be due to the sample of this study was all children and most of the cases were congenital cataracts. According to Bashour, ${ }^{14}$ unilateral cataracts are commonly the result of a sporadic incidents such as ocular abnormalities and trauma, while bilateral cataracts are mostly due to congenital diseases caused by several factors including genetic or chromosomal abnormalities, prematurity, TORCH infection, and other diseases. The results of this study are also in line with Ambroz, et al., ${ }^{15}$ which stated that of the 63 pediatric cataract surgery patients in Switzerland, 37 patients had bilateral cataracts while only 26 other had unilateral cataracts.

From 32 eyes of pediatric cataract patients who underwent pediatric cataract surgery, 24 eyes (75\%) had intraocular lens implanted. Surgical procedures followed by implantation of intraocular lens had been confirmed improving patients' visual quality, although the risk of complications such as turbidity of the posterior lens capsule and glaucoma can still be a problem in pediatric patients. ${ }^{1}$ With the development of surgical techniques and the implantation of intraocular lens, the results in pediatric cataract surgeries have dramatically improved. ${ }^{16}$ The results of this study are similar to Ambroz, et al. ${ }^{15}$ who stated that of 63 patients (94 eyes), 35 patients (49 eyes) received intraocular lens implantation, while 28 other patients (45 eyes) were left aphakic. Biler, et al., ${ }^{17}$ found that from 78 eyes implanted with intraocular lens, 66 eyes (84.6\%) showed the development of BCVA by 2 lines. This proves that the implantation of intraocular lens can improve the visual quality of patients with pediatric cataract surgery, although post-operative complications shoul be recognized. ${ }^{17}$

The mean pre-operative IOP of pediatric cataract patients was $13.05 \mathrm{mmHg}$ with a standard deviation of 3.36. Whereas the mean post-operative IOP for pediatric cataract patients was $13.36 \mathrm{mmHg}$ with a standard deviation of 3.39. Overall, there were non-statistically significant differences between pre- and post-operative IOP. There was an increase in post-operative IOP with an average increase of $0.31 \mathrm{mmHg}$. Nevertheless, even after the post-operative IOP increases, it is still in the normal range of $10-20 \mathrm{mmHg}{ }^{18}$ IOP of more than $21 \mathrm{mmHg}$ can be categorized as ocular hypertension and might develop a glaucoma if IOP has reached more than $26 \mathrm{mmHg}^{6}$ The 
increase in IOP after pediatric cataract surgery can be caused by several things, including post-operative inflammation and anaesthetic effect. This study showed similar results to Chen, et al. ${ }^{18}$, which stated that $58.7 \%$ of patients with pediatric cataract surgery experienced an increase in post-operative IOP. On the contrary, other studies found only $20.7 \%$ of patients with pediatric cataract surgery found an increase in IOP post-operatively. ${ }^{19}$ This differences can be caused by differences in the sample size, operating techniques, types of anaesthesia, and IOP measurement tools that may differ in accuracy.

The mean pre-operative IOP in pediatric cataract surgery patients aged younger than 24 months old was $12.39 \mathrm{mmHg}$ with a standard deviation of 3.50 and the mean post-operative IOP was $13.58 \mathrm{mmHg}$ with a standard deviation of 3.56. There was an increase from preoperative IOP to post-operative IOP, with an average increase of $1.19 \mathrm{mmHg}$. Whereas, patients with pediatric cataract surgery at the age older than 24 months old had an average pre-operative IOP of $14.15 \mathrm{mmHg}$ with a standard deviation of 2.92 and a mean post-operative IOP of $13.00 \mathrm{mmHg}$ with a standard deviation of 3.21 . In contrast to the age group younger than 24 months old, it turns out that in the older group, there was a decrease in post-operative IOP with an average decrease of 1.15 $\mathrm{mmHg}$. This can occur because post-operative glaucoma is indeed greatly influenced by the age at surgery. The risk of developing post-cataract glaucoma is significantly lower in surgeries of children aged more than 9 months old. ${ }^{20}$ Compared to children who underwent surgery at the age of 2 years old or more, the risk of glaucoma increases between 5.8-9.4 times among children who underwent surgery in the first 8 months of life. ${ }^{20}$ This might be caused by the filtration angle in the eye of neonates which is susceptible to post-operative inflammation. ${ }^{18}$ Haargaard, et al. ${ }^{20}$ also stated that in the 5 years post-cataract surgery, glaucoma develops in about $12.7 \%$ of patients who underwent cataract surgery at the age younger than 9 months old, while in patients who underwent the surgery later, only $1.8 \%$ develop glaucoma. However, there are some things that must be considered, that the occurrence of glaucoma in this age group is not only caused by an increase in IOP, but can also due to a decrease in IOP. In addition, corneal thickness can also affect IOP results. Patients with thick corneas tend to have higher IOP. Although post-operative IOP did not elevate drastically, IOP monitoring and follow-up in pediatric cataract surgery patients must be routinely performed to prevent the development of glaucoma.

The mean pre-operative IOP in aphakic patients was $10.63 \mathrm{mmHg}$ with a standard deviation of 3.15 and the mean post-operative IOP was $12.29 \mathrm{mmHg}$ with a standard deviation of 3.89. There was an increase from preoperative IOP to post-operative IOP, with an average increase of $1.66 \mathrm{mmHg}$. Whereas, pseudophakic patients had a mean pre-operative IOP of $13.86 \mathrm{mmHg}$ with a standard deviation of 3.08 and a mean post-operative IOP of $13.72 \mathrm{mmHg}$ with a standard deviation of 3.21 . Unlike the aphakic group, it turns out that in the pseudophakic group, there was a decrease in post-operative IOP with an average decrease of $0.14 \mathrm{mmHg}$. According to Sahin, et al., ${ }^{21}$ of 249 eyes without intraocular lens, 12 (4.8\%) of them had a very high IOP and developed glaucoma. Meanwhile, from 220 eyes that were implanted with intraocular lens, no patients suffered from post-operative glaucoma. Asrani, et al. ${ }^{22}$ also stated that of 124 eyes in aphakic patients, there were 14 eyes (11.3\%) suffering from glaucoma, whereas in 377 eyes that received intraocular lens implantation, only 1 eye had a glaucoma. Trivedi, et al. ${ }^{19}$ also reported that 8
(17\%) of 47 eyes without intraocular lens were diagnosed with glaucoma, while only $10(3.8 \%)$ of 266 eyes with intraocular lens implanted were diagnosed with glaucoma. Glaucoma in aphakic patients is caused by high IOP that may be due to the absence of a lens. The aphakic condition is causing the disappearance of support for trabecular meshwork. Simon, et al. ${ }^{23}$ stated that the risk of aphakic glaucoma can occur if cataract surgery is performed at a very early age. This variability has been associated with differences in patient population, type of cataract, age at surgery, definition of glaucoma, and length of follow-up. In the study of Sahin, et al.,21 which refers to the previous studies, the age at surgery is also a major factor because very young patients tend to develop aphakic condition. Some other studies also claim that intraocular implantation can reduce the risk of post-pediatric cataract glaucoma. ${ }^{21}$ Intraocular lens implantation could prevent toxic vitreous metabolites from entering the anterior chamber. It can be inferred that intraocular lens implantation, in some cases, is protective against glaucoma. ${ }^{21}$ Follow-up must still be performed in pseudophakic patients to avoid the development of post-operative glaucoma.

\section{Conclusion}

Based on the results, it can be concluded that the mean pre-operative IOP in pediatric cataract surgery patients at Dr. Soetomo General Hospital Surabaya in the period of 1 January 2017 to 31 August 2019 was 13.05 $\mathrm{mmHg}$, while the mean post-operative IOP was 13.36 $\mathrm{mmHg}$. There was no difference found between pre- and post-operative IOP of pediatric cataract surgery.

It is necessary to fill in IOP data in a more complete medical records, observation of IOP in adolescent or adult patients who previously had pediatric cataract surgery, as well as further research with a larger sample size. A longer study period should be performed, hence the results can better represent the population.

\section{Acknowledgement}

Lavish praises are given to those who have participated in this study. Deepest gratitude is given to the mentors for the unbending guidance during the processes of this study. Praises should also be given to the staff of Department of Research and Development and medical record in Dr. Soetomo General Hospital Surabaya, who had been a major help in the ethical licenses bureaucracy and data collection. Last but not least, for the dearest colleagues and friends who had been a great support throughout this study.

\section{CONFLICT OF INTEREST}

The author stated there is no conflict of interest in this study.

\section{REFERENCES}

1. World Health Organization. Priority Eye Diseases. who, https://iposc.org/sites/default/files/pehdocuments/who_priority-child_blindness_0.pdf (2014).

2. Kementerian Kesehatan Republik Indonesia. Menkes: Katarak Penyumbang Kebutaan Terbesar. Kementerian Kesehatan Republik Indonesia, 
https://www.kemkes.go.id/article/print/18090900003/menk es-katarak-penyumbang-kebutaan-terbesar.html (2018).

3. Khokhar S, Pillay G, Dhull C, Agarwal E, Mahabir M, Aggarwal P. Pediatric Cataract. Indian J Ophthalmol 2017; 65: 1340-1349.

4. Medsinge A, Nischal K. Pediatric Cataract: Challenges and Future Directions. Clin Ophthalmol 2015; 9: 77-90.

5. Parks M, Johnson D, Reed G. Long-Term Visual Results and Complications in Children with Aphakia. A Function of Cataract type. Ophtalmology 1993; 100: 826-40.

6. Rabiah P. Frequency and Predictors of Glaucoma after Pediatric Cataract Surgery. Am J Ophthalmol 2004; 137: 30-37.

7. Vishwanath M, Cheong-Leen R, Taylor D, Russel-Eggitt I, Rahi J. Is Early Surgery for Congenital Cataract a Risk Factor for Glaucoma? Br J Ophthalmol 2004; 88: 905-10.

8. Joseph E, Meena C. Pediatric Cataract. Kerala J Ophthalmol 2018; 30: 162-171.

9. He W, Sun T, Yang J, Qin G, Wu Z, Zhu X, Lu Y. Analysis of Factors Associated with the Ocular Features of Congenital Cataract Children in the Shanghai Pediatric Cataract Study. J Ophthalmol; 2017. Epub ahead of print 2017. DOI: $10.1155 / 2017 / 8647435$

10. Lin $\mathrm{H}$, Yang $\mathrm{Y}$, Chen $\mathrm{J}$, Zhong $\mathrm{X}$, Liu Z, Lin Z. Congenital Cataract: Prevalence and Surgery Age at Zhongshan Ophthalmic Center (ZOC). PLOS One 2014; 9: e101781.

11. Katibeh M, Eskandari A, Yaseri M, Hosseini S, Ziaei H. The Gender Issue in Congenital and Developmental Cataract Surgery. J Ophthalmic Vis Res 2013; 8: 308-313.

12. Gilbert C, Lepvrier-Chomette N. Gender Inequalities in Surgery for Bilateral Cataract among Children in Low-Income Countries: A Systematic Review. Ophtalmology 2016; 123: 1245-51.

13. Repka MX, Dean TW, Lazar EL, Yen KG, Lenhart PD, Freedman SF, Hug D, Rahmani B, Wang SX, Kraker RT, Wallace DK \& Pediatric Eye Disease
Investigator Group. Cataract Surgery in Children from Birth to Less than 13 Years of Age: Baseline Characteristics of the Cohort. Ophtalmology 2016; 123: 2462-2473.

14.Bashour M. Congenital Cataract. Medscape, https://emedicine.medscape.com/article/1210837overview (2018).

15. Ambroz S, Töteberg-Harms $M$, Hanson J, Funk J, Barthelmes D, Gerth-Kahlert C. Outcome of Pediatric Cataract Surgeries in a Tertiary Center in Switzerland. J Ophthalmol. Epub ahead of print 2018. DOI: https://doi.org/10.1155/2018/3230489.

16. Javadi M. Pediatric Cataract Surgery. J Ophthalmic Vis Res 2009; 4: 199-200.

17. Biler E, Yıldırım S, Üretmen Ö, et al. Long-term Results in Pediatric Developmental Cataract Surgery with Primary Intraocular Lens Implantation. Turk $J$ Ophthalmol 2018; 48: 1-5.

18. Lin H, Chen W, Luo L, Zhang X, Chen J, Lin Z. Ocular Hypertension after Pediatric Cataract Surgery: Baseline Characteristics and First-Year Report. PLoS One 2013; 8: e69867.

19. Tatham A, Odedra N, Tayebjee S, Anwar S, Woodruff $\mathrm{G}$. The Incidence of Glaucoma following Paediatric Cataract Surgery: a 20-year Retrospective Study. Eye 2010; 24: 1366-75.

20. Haargaard B, Ritz C, Oudin A, Wohlfahrt J, Olsen T, Melbye M. Risk of Glaucoma after Pediatric Cataract Surgery. Invest Ophthalmol Vis Sci 2008; 49: 1791-6.

21. Sahin A, Caça I, Cingü AK, Türkcü FM, Yüksel H, Sahin M, Cinar Y, Ari S. Secondary Glaucoma after Pediatric Cataract Surgery. Int J Ophthalmol 2013; 6: 216-220

22. Asrani S, Freedman S, Hasselblad V, Buckley EG, Egbert J, Dahan E, Gimbel $H$, Johnson D, McClatchey S, Parks M, Plager D, Maselli E. Does Primary Intraocular Lens Implantation Prevent 'aphakic' Glaucoma in Children? J Am Assoc Pediatr Ophthalmol Strabismus 2000; 4: 33-39.

23. Simon J, Mehta N, Simmons S, et al. Glaucoma after Pediatric Lensectomy/Vitrectomy. Ophtalmology 1991; 98: 670-4. 